\title{
Ultimate Behavior of Composite Castellated Beams under Vertical Loads
}

\author{
R. E. S. Ismail \\ Department of Civil \\ Engineering, Alexandria \\ University, Alexandria, Egypt \\ (On Secondment to Beirut Arab \\ University-Tripoli-Branch, \\ Lebanon)
}

\author{
A.S. FAHMY \\ Department of Civil \\ Engineering, Alexandria \\ University, Alexandria, Egypt
}

\author{
N. M. Tawfik \\ Department of Civil \\ Engineering, Alexandria \\ University, Alexandria, Egypt
}

\begin{abstract}
The aim of this paper is to carry out extensive numerical investigations about the effect of various parameters on both buckling loads and ultimate behavior of continuous partially composite castellated beams under vertical loads. Efficient nonlinear 3D Finite Element Model using ABAQUS software is developed. The initial geometric imperfection and material nonlinearities were carefully considered in the analysis. At first, Eigenvalue analysis is carried out to obtain the elastic buckling load and the corresponding buckling mode. In order to trace the entire load-deflection curve, the first buckling mode is factored and inserted into the inelastic geometrical nonlinear analysis of the beam as initial imperfection. The reliability of the model is demonstrated by comparisons with experiments and with alternative numerical and analytical analyses for continuous composite beam. Different modeling techniques available in ABAQUS are used for the modeling of the shear connectors. In addition, a parametric study is carried out to investigate the effect of change in cross-section geometries, beam length, alignment of stiffeners, concrete strength, steel strength and concrete slab thickness on the both buckling and the overall structural behavior of continuous partially composite castellated beams under vertical loads. A total of 96 partially composite castellated beams are studied. Based on the findings of the finite element results, a number of recommendations on the methods of modeling and on the design of continuous steel-concrete composite castellated beams are suggested.
\end{abstract}

\section{Keywords}

Castellated beams, partially composite beams, Distortional buckling, Finite element.

\section{INTRODUCTION}

Castellated beams are fabricated through two phases, first one cutting a rolled beam's web in a zigzag pattern along it's center line and second one rejoining the two halves by welding, so the overall beam depth is increased by $50 \%$ and an enhanced structural performance against bending is achieved. The application of these structural members may lead to substantial economies of material and other advantages including greater bending rigidity, larger section modulus, optimum self-weight-depth ratio, economic construction, ease of services through the web openings. However, the castellation of beams results in distinctive failure modes, detailed by Nethercot and Kerdal (1982). They concluded that under given applied transverse or coupling forces, failure is likely to occur by one of the following modes: vierendeel or shear mechanism, flexural mechanism, lateral torsional buckling of the beam, rupture of welded joints, shear buckling of web posts, and compression buckling of web posts.
Comparing to non-composite castellated beams, a few work has been done on composite castellated beams. Composite castellated beams can be employed in long span floors where the services can pass through the web-openings leading to minimum floor heights. The composite action develops a force in the concrete slab which in turns increases the effective depth of the beam and raises the neutral axis closer to the top flange, by this way, an increase in the stiffness and strength can be achieved. However, similar to the noncomposite castellated beams, the local bending and shear strength of the web posts and upper and lower tees can limit the load carrying capacity of a composite beam. Larnach and Park (1964) have conducted tests on six different castellated composite T-beams under heavy shear loading to study the composite action between castellated beams and a concrete slab. Tests on two composite hybrid castellated beams subjected to uniformly distributed load were performed by Giriyappa and Baldwin (1966). Hartono and Chiew (1996) conducted experimental and numerical studies on six composite half castellated beams, one half of a castellated beam with a horizontal flange plate welded to the top of the web posts and shear studs attached to the plate. Megharief (1997) tested up five castellated composite beams to failure at the Structural Engineering Laboratory of McGill University, where he observed the behavior of simply supported composite castellated beams under the sagging moment, and then modeled their behavior numerically with use of the finite element (FE) technique. Gizejowski and Salah (2011) investigated the behavior of statically indeterminate single and multi-span composite beams (plain-webbed and castellated) using the FE simulation technique. Regarding to the stability behavior of slender section steel concrete composite beams with web openings, experimental investigation and numerical finite element modeling were established by Salah and Gizejowski (2008a, 2008b) where a full composite action was assumed. Little investigations of the strength in continuous castellated composite beam systems were done compared to plain composite beams, where different instability effects start to play an important role, especially in the hogging moment zone, Gizejowski and Salah (2007), where the laterally unrestrained bottom flange is sensitive to a local and/or a restrained distortional buckling phenomenon. In this paper, efficient nonlinear 3D Finite Element Model using ABAQUS software is developed for the analysis of steel-concrete continuous composite castellated beams with partial shear connection. The accuracy and reliability of the model is demonstrated by analyzing a continuous composite beam. A comparison between the numerical results with the corresponding experimental data is made and good agreements are found. In addition, a parametric study is carried out to investigate the effect of different parameters on the both buckling and the overall 
structural behavior of continuous partially composite castellated beams under vertical loads.

\section{FINITE ELEMENT MODELING}

In this study, the finite element software ABAQUS (2008) is used for the analysis of partially composite castellated beams. Doubly curved shell elements 4-node and 3-node with reduced integration S4R and S3R, were used to model the flanges, web and the concrete slab, as shown in Figure 1. The steel reinforcing bars in the concrete slabs were modeled in the present study as smeared layers (rebar layers) with a constant thickness in shell elements. The material property of reinforcing bars was defined in the material section.

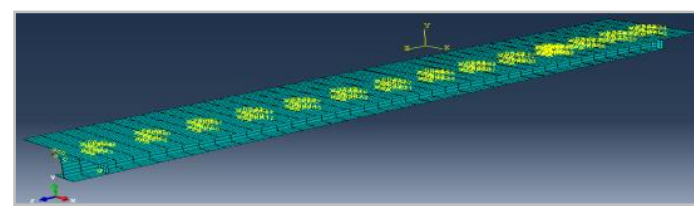

Fig 1: Typical finite element mesh for composite beams

As for steel material, the stress-strain relationship is linear elastic up to yielding, perfectly plastic between the elastic limit $\left(\varepsilon_{y}\right)$ and the beginning of strain hardening and follows the constitutive law used by Gattesco (1999) for the strain hardening branch:

$$
\sigma_{\boldsymbol{s}}=\boldsymbol{f}_{\boldsymbol{s y}}+\boldsymbol{E}_{\boldsymbol{s h}} \varepsilon_{\boldsymbol{s}}-\varepsilon_{\boldsymbol{s h}} \cdot\left(1-\boldsymbol{E}_{\boldsymbol{s h}} \cdot \frac{\varepsilon_{\boldsymbol{s}}-\varepsilon_{\boldsymbol{s h}}}{4 \boldsymbol{f}_{\boldsymbol{s u}}-\boldsymbol{f}_{\boldsymbol{s} \boldsymbol{y}}}\right)
$$

Where $f_{s y}$ and $f_{s u}$ are the yield and ultimate tensile stresses of the steel component, respectively; $E_{s h}$ and $\varepsilon_{s h}$ are the strain hardening modulus and the strain at strain hardening of the steel component, respectively, as shown in Figure 2.

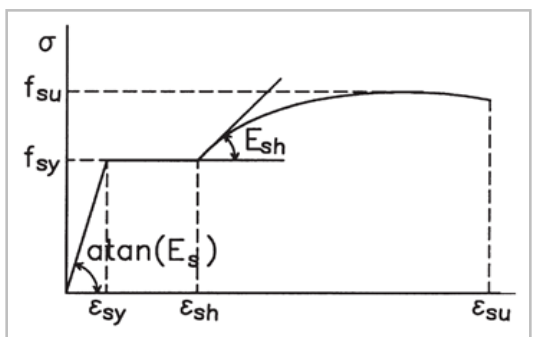

Fig 2: Steel and reinforcement stress strain curve, Gattesco (1999)

As for concrete material, the SC model (smeared crack model) available in ABAQUS is used. The uniaxial stress-strain relationship for concrete proposed by Carreira and Chu (1985), shown in Figure 3, is adopted in the present study. The concrete tensile strength and the Poisson's ratio are assumed as $1 / 10$ of its compressive strength and 0.2 , respectively. The concrete slab compressive strength is taken as the actual cylinder strength test value and is evaluated by:

$$
\boldsymbol{f}_{\boldsymbol{c}}=\frac{\boldsymbol{f}_{\boldsymbol{c}}^{\prime} \gamma_{\boldsymbol{c}}\left(\frac{\varepsilon_{\boldsymbol{c}}}{\varepsilon_{\boldsymbol{c}}^{\prime}}\right)}{\gamma_{\boldsymbol{c}}-1+\left(\frac{\varepsilon_{\boldsymbol{c}}}{\varepsilon_{\boldsymbol{c}}^{\prime}}\right)^{\gamma_{\boldsymbol{c}}}}
$$

Where $f_{c}=$ compressive stress in concrete, $\varepsilon_{c}=$ compressive strain in concrete, $f_{c}^{\prime}=$ cylinder compressive strength of concrete, $\varepsilon_{c}^{\prime}=$ strain corresponding to $f_{c}^{\prime}$ and $\gamma_{c}$ is defined by:

$$
\gamma_{c}=\left|\frac{\boldsymbol{f}_{\boldsymbol{c}}^{\prime}}{32.4}\right|^{3}+1.55
$$

The concrete elastic modulus is evaluated according to Eurocode 4 (1992), where $\gamma_{c}$ is equal to $24 \mathrm{kN} / \mathrm{m}^{3}$.

$$
E_{c}=9500 f_{c}+8^{1 / 3}\left(\frac{\gamma_{c}}{24}\right)^{1 / 2}
$$

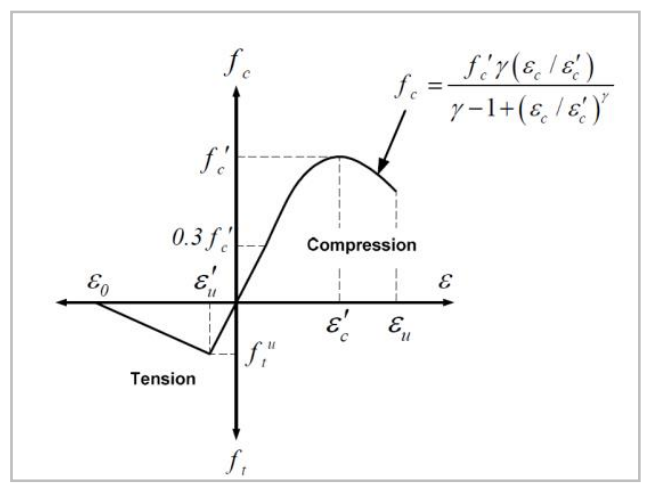

Fig 3: Concrete stress strain curve, Carreira and and Chu (1985)

Defining the strain-softening behavior for cracked concrete is modeled with tension stiffening model shown in Figure 4, where the stress strain relationship assumes that the tensile stress increases linearly with an increase in tensile strain up to concrete cracking, then the tensile stress decreases linearly to zero as the concrete softens. The value in tension stiffening is an important parameter that affects the solution of a nonlinear analysis of reinforced concrete. For heavily reinforced concrete slabs, the total strain at which the tensile stress is zero is usually taken as 10 times the strain at failure in the tension stiffening model. However, it has been found that this value was not adequate for concrete slabs in composite beams (Basker et. al. 2002, Liang et al. 2005).

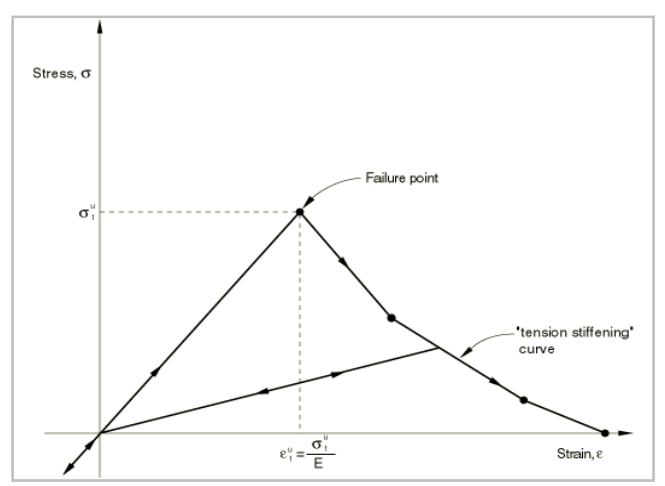

Fig 4: "Tension stiffening" model, Hibbitt, Karlsson and Sorensen, (2008)

ABAQUS provides several ways for modeling of shear connection between the concrete slab and the steel top flange, among these ways the connector element. Connector elements called CARTESIAN connectors were used, which provide a connection between two nodes where the response in three 
local connection directions is specified, (ABAQUS 2008). Linear and Nonlinear elastic connector elements plus Contact interactions were used for modeling of partial shear connection, where the force values and relative displacements (slip) of the studs were used as input data for the nonlinear connectors. The load-slip relationship of the connector is represented by the equation (Figure 5):

$$
Q=Q_{u} \cdot 1-e^{-\beta \cdot s}{ }^{\alpha}
$$

Where $Q_{u}$ is the ultimate load of the connector, and $\alpha$ and $\beta$ are coefficients to be determined from the experimental results.

To model the hard contact behavior between two surfaces (the concrete slab and the steel top flange) with no penetration or separation, the surface interaction relationship "no separation" available in ABAQUS is used.

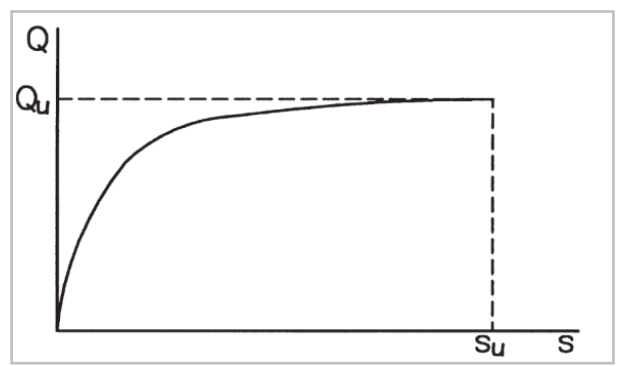

Fig 5: Load-Slip curve of the shear studs, Gattesco (1999)

Only half of the beam test was modeled due to symmetry as shown Figure 2. Boundary conditions were prescribed to prevent the rigid body motion of the beam during the buckling and nonlinear analysis. The beam was subjected to distributed static load which was applied incrementally. At first, Eigenvalue analysis is carried out to obtain the elastic buckling load and the corresponding buckling mode. The first buckling mode is factored by a magnitude of $L_{u} / 1000$ where $L_{u}$ is the length between points of effective bracing. In order to trace the entire load-deflection curve, the factored first buckling mode is inserted as initial imperfection into the inelastic geometrical nonlinear analysis of the beam.

\section{VERIFICATION OF FINITE \\ ELEMENT MODELING}

A comparison between the numerical results obtained by the computer program ABAQUS and the experimental results reported by Ansourian (1981) for continuous composite beam (beam CTB 4) shown in Figure 6 is made.

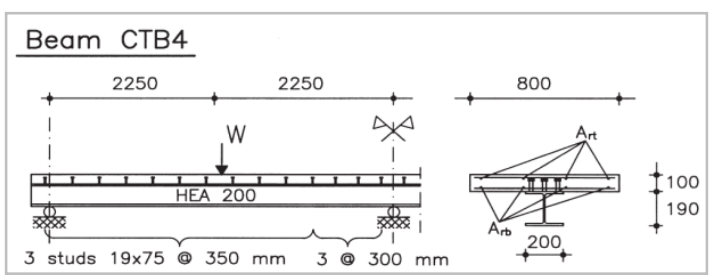

Fig 6: Continuous test beam CTB4 layout

In the present study, three values of the tension stiffening $0.01,0.05$ and 0.09 are used and it was found that for the continuous composite beam tested by Ansourian (1981) a total strain of 0.09 gives the best agreement with the experiment. Also it can be concluded that for partial shear connection, using the Nonlinear elastic connector elements and Contact interactions gives the best agreement with the experiment. Figure 7 shows the load-deflection curve of the composite beam CTB 4 obtained by the present study compared with that obtained by experiment and with that obtained by alternative numerical study, Gattesco (1999).

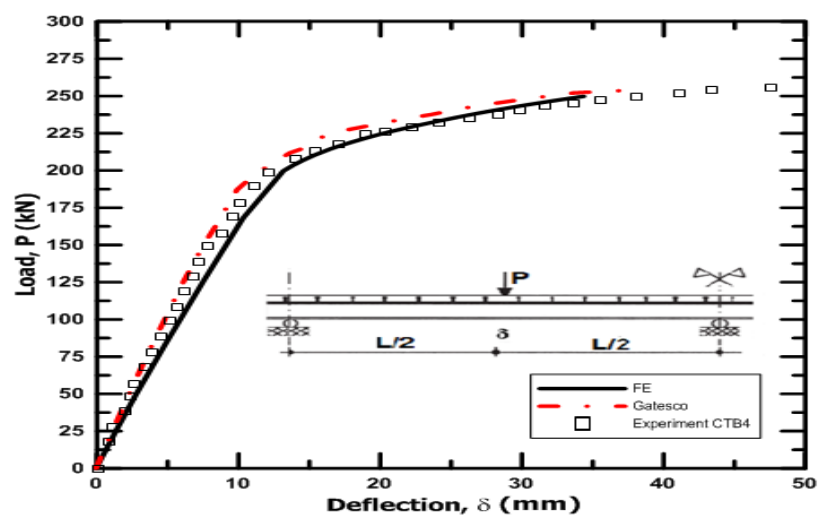

Fig 7: Validation of the finite element model

Figure 10 shows that the initial stiffness of the composite beam predicted by the present finite element model is same as that of the experimental one. Also, the model reached to $98 \%$ of the ultimate load of the experimental value for beam CTB 4 and conformed to the experimental observation of failure of the composite beam CTB 4 by crushing of the top concrete slab at mid-span and at the middle support. It can be concluded that the present finite element model is reliable and conservative in predicting the ultimate strength of composite beams.

\section{PARAMETRIC STUDY}

Based on the previous experimental verification of the $\mathrm{FE}$ analysis, a parametric study on buckling of continuous steel concrete composite castellated beams in negative bending is further carried out to investigate the influence of different parameters on the strength, elastic stiffness and ductility of such beams. The ductility of the beams can be measured by the toughness ratio (TR) Dabaon (2002).

$$
T R=T_{u} / T_{e}
$$

Where, $T_{u}$ is the area under the ultimate curve of the load deflection relationship and $T_{e}$ is the area under the elastic curve.

A total of 96 models are built and solved using ABAQUS. Only half length of the beam is modeled due to symmetry. The deflection at mid-span of the composite castellated beams is monitored in the analysis. The composite castellated beams are designed on a level of shear connection $(\eta=1)$, where the beams exhibit full shear connection (conformed by experimental findings presented by Donahey and Darwin (1986). This value is defined as the ratio between the shear connection capacity and the weakest element capacity (concrete slab or steel beam). The shear connectors are designed according to the Eurocode 4 (1992), where the nominal stud strengths are given by:

$$
q_{n} \leq\left\{\begin{array}{c}
0.29 d^{2} f_{c k} E_{c m} \\
0.8 f_{u}\left(\frac{\pi d^{2}}{4}\right)
\end{array}\right.
$$


Where $d$ is the diameter of the shank of the stud, $f_{c k}$ is the characteristic cylinder strength of the concrete, Ecm is the nominal value of the secant modulus of the concrete, $f_{u}$ is the specified ultimate tensile strength of the material of the stud but not greater than $500 \mathrm{~N} / \mathrm{mm}^{2}$. There are three criteria used in the present study to define the ultimate load. These criteria are shear connector' failure (by monitoring the slip of the studs), divergence (due to the large amounts of cracking) and distortional buckling of the beam web (Figure 8).

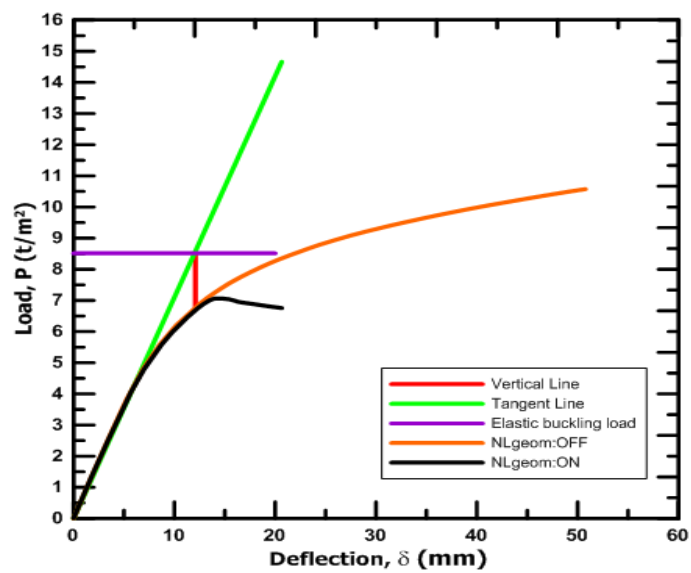

Fig 8: Buckling failure criteria

\subsection{Effect of Changes in Web Geometry}

Three cases $\left(\mathrm{B}^{*}, \mathrm{C}^{*}\right.$ and $\left.\mathrm{D}^{*}\right)$ of the web are studied in addition to the normal castellated web $\mathrm{A}^{*}$ in order to improve the buckling capacity of the continuous composite castellated beam; figures 9-11. A number of beams varying in their span to depth ratios and web slenderness were studied to investigate the effect of the previous web statuses on the overall behavior of the continuous composite castellated beams. Samples of the load deflection curves are shown in figure 12 .

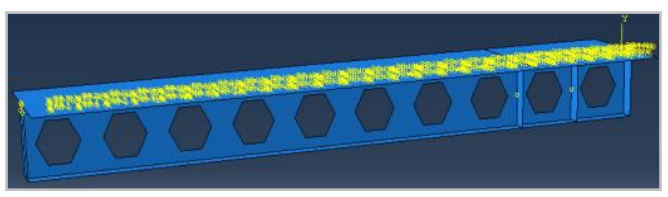

Fig 9: Web status B* (Vertical stiffeners)

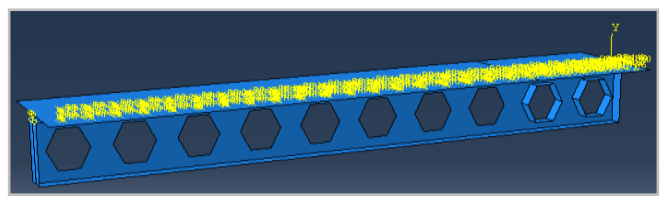

Fig 10: Web status $C^{*}$ (Stiffeners around openings)

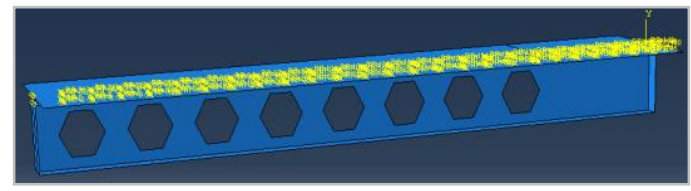

Fig 11: Web status $D^{*}$ (openings starting at fifth of span)

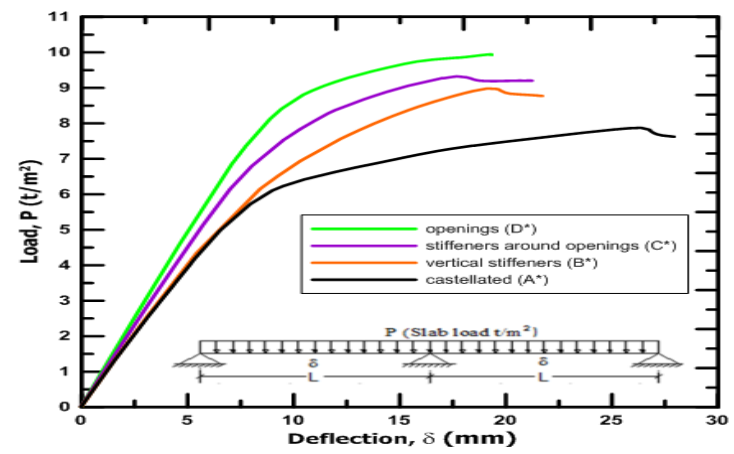

Fig 12: Load deflection curve of beams with $\left(L / h_{w}=10 \&\right.$

$$
\left.h_{w} / t_{w}=86\right)
$$

The results show that the modifications made to the castellated web affected clearly the ultimate load, the ductility and the elastic stiffness of the composite beams. Figures 13, 14 and 15 show the effect of the changes of the web on the ultimate load, ductility and initial stiffness, respectively, on beams with different web slenderness with span to depth ratio $=10$.

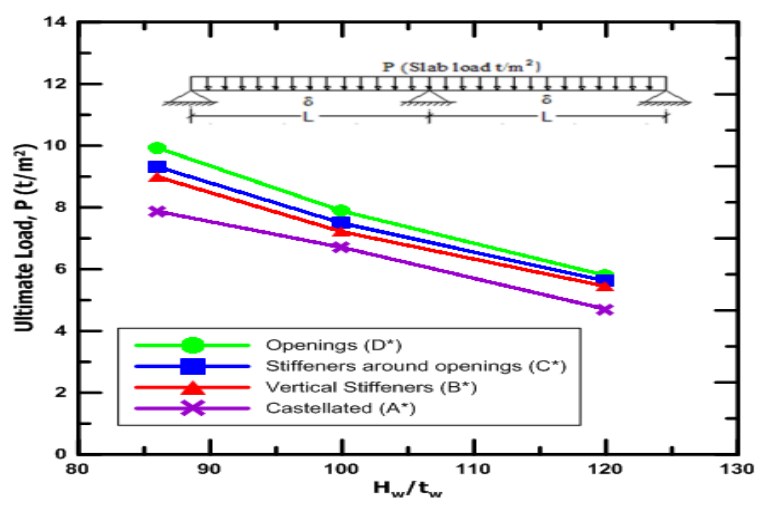

Fig 13: Effect of changes in web geometry on ultimate load for different $h_{w} / t_{w}$

From Figure 13, we can conclude that the values of the ultimate loads that come from the three statuses of the castellated web $\left(\mathrm{B}^{*}, \mathrm{C}^{*}, \mathrm{D}^{*}\right)$ become closer to each other as the web slenderness increases and vice versa by decreasing the web slenderness. As an example on the percentages of increase in the ultimate loads achieved, for $h_{w} / t_{w}=100$, case $\mathrm{B}^{*}$ causes an increase of ultimate load by $7.5 \%$, case $\mathrm{C}^{*}$ causes an increase by $11.6 \%$ and case $\mathrm{D}^{*}$ causes an increase by $17.8 \%$.

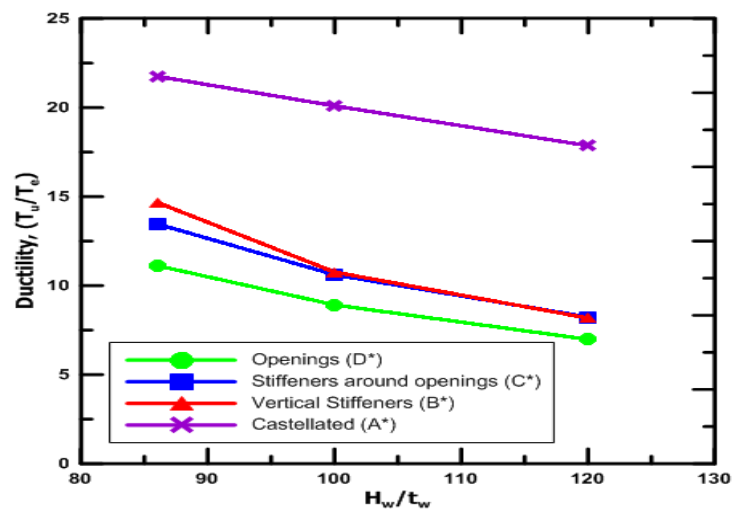

Fig 14: Effect of changes in web geometry on ductility for different $h_{w} / t_{w}$ 


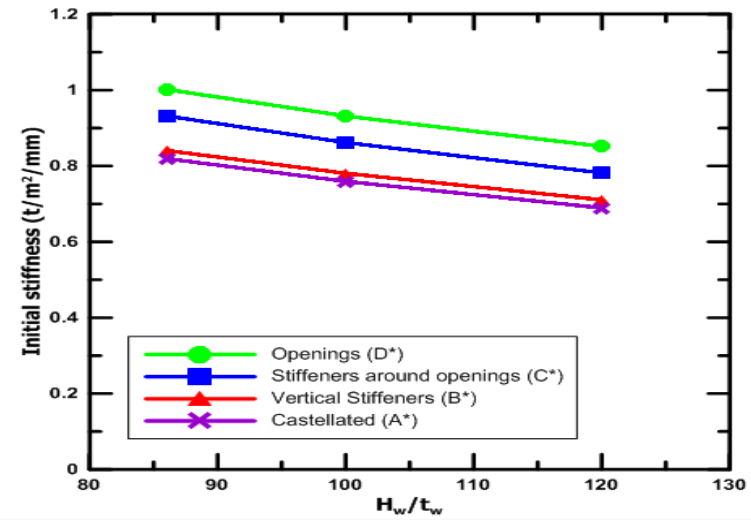

Fig 15: Effect of changes in web geometry on initial stiffness for different $h_{w} / t_{w}$

From Figure 14, it is clear that the three cases $\mathrm{B}^{*}, \mathrm{C}^{*}$ and $\mathrm{D}^{*}$ affects clearly the ductility of the normal castellated beams, as they cause an obvious decrease in ductility less than the normal case (A*) by $43.7 \%, 45.8 \%$ and $54.9 \%$ respectively in the average with respect to different web slenderness. From Figure 15 , we can conclude that case $D^{*}$ gives high values for the initial stiffness followed by case $\mathrm{C}^{*}$, while case $\mathrm{B}^{*}$ gives low percentages of increase, so it is not recommended when high initial stiffness is required. As an example on the percentages of increase in the initial stiffness achieved, for $h_{w}$ $/ t_{w}=100$, case $\mathrm{B}^{*}$ causes an increase by $2.6 \%$, case $\mathrm{C}^{*}$ causes in an increase by $13.2 \%$ and case $\mathrm{D}^{*}$ causes an increase by $22.4 \%$.

\subsection{Effect of Material Properties}

The beams that were built and solved in order to investigate the effect of material properties are chosen on the basis of studying the effect on the status $\mathrm{D}^{*}$ (starting the web openings after the negative moment region) as a proposed solution to enhance the buckling capacity for beams with different web slenderness and span to depth ratios.

\subsubsection{Effect of Steel Strength}

Variation in the value of yield and ultimate stresses (conforming to EC3 (2007)) is used to study the effect of the steel strength utilized in the steel beams. Samples of the load deflection curves for beams with span to depth ratio $=15$ are shown in figure 16. It is found that the initial stiffness doesn't change as it depends on the constant modulus of elasticity, while the behavior of the composite castellated beams in the plastic stage (the start of yielding and the value of ultimate load) is improved clearly with the variation of steel strength.

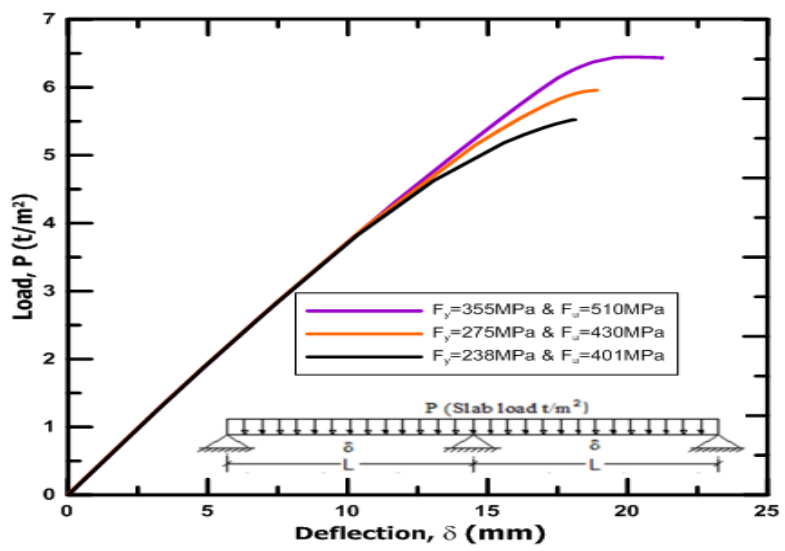

Fig 16: Load deflection curve of S60, S69 \& S75
For different web slenderness, the effect of changes in steel strength on the ultimate load is shown in Figure 17, where there is an obvious increase in the ultimate load resulted from increasing the steel strength. As an example, for $h_{w} / t_{w}=86$ (web status $\mathrm{D}^{*}$ ), the percentage of increase in the ultimate load is $7.6 \%$ and $16.6 \%$ for type 2 and type 3 respectively.

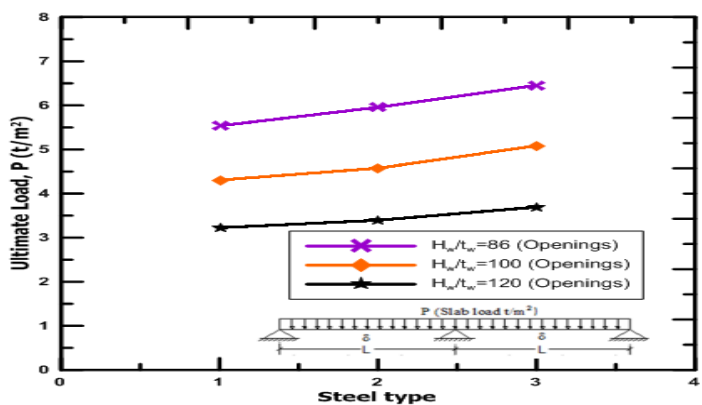

Fig 17: Effect of changes in steel strength on ultimate load

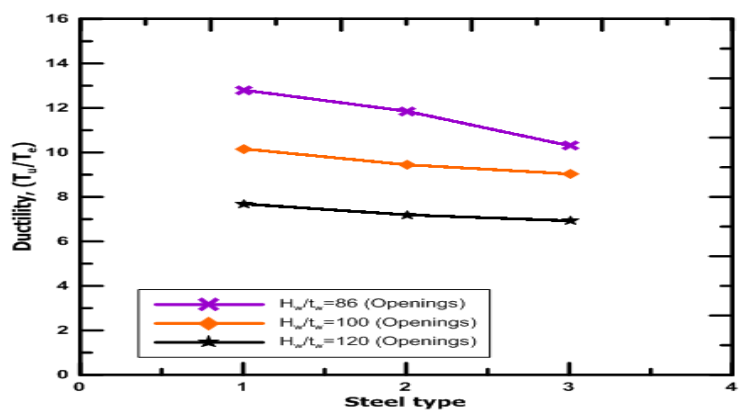

Fig 18: Effect of changes in steel strength on ductility

Figure 18 shows the effect of changes in steel strength on the ductility, where the ductility decreases by increasing the steel strength in average by $15 \%$ and $30 \%$ for steel types $2 \& 3$, respectively.

\subsubsection{Effect of Concrete Strength}

This parameter is studied through the use of different concrete compressive strengths $(34 \& 40 \mathrm{MPa})$ in the slab and in the associated push-out tests represented by the load-slip curves of shear connectors, Gatesco (1999) and Mashaly et. al. (2010). Samples of the load deflection curves for beams with span to depth ratio $=15$ are shown in figure 19 , where the variation of concrete strength has almost no influence on the initial stiffness, but we can achieve a small increase in the strength and ductility by increasing the concrete strength (Figures 20 and 21).

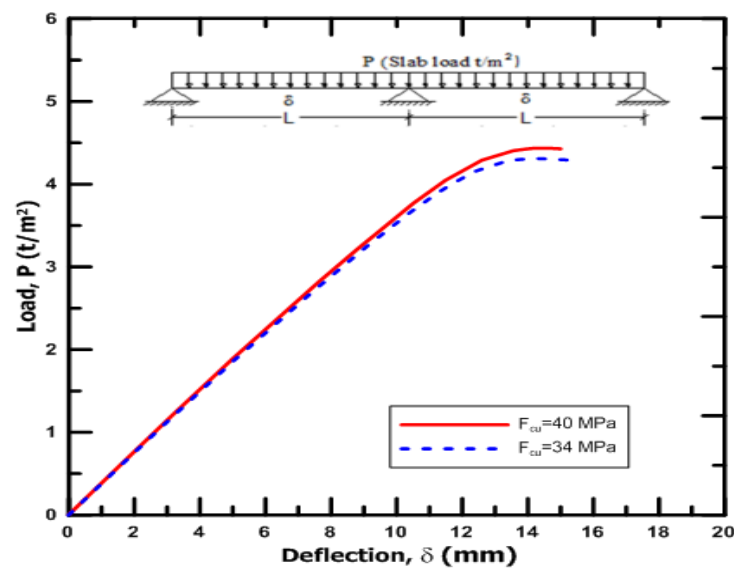

Fig 19: Load deflection curve of S57 \& S62 


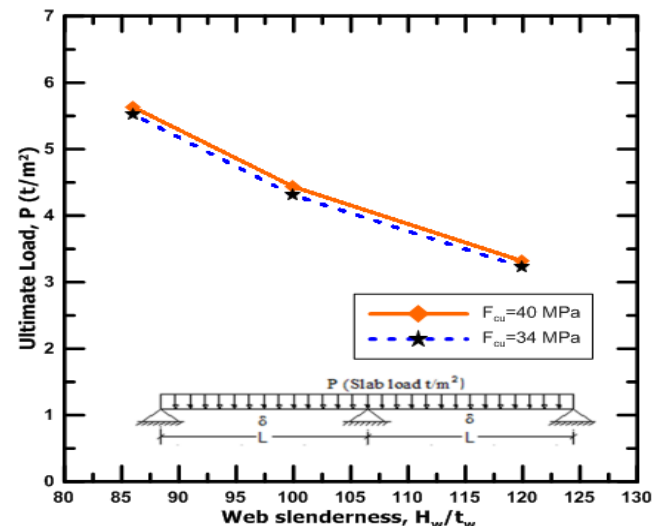

Fig 20: Effect of changes in concrete strength on ultimate load

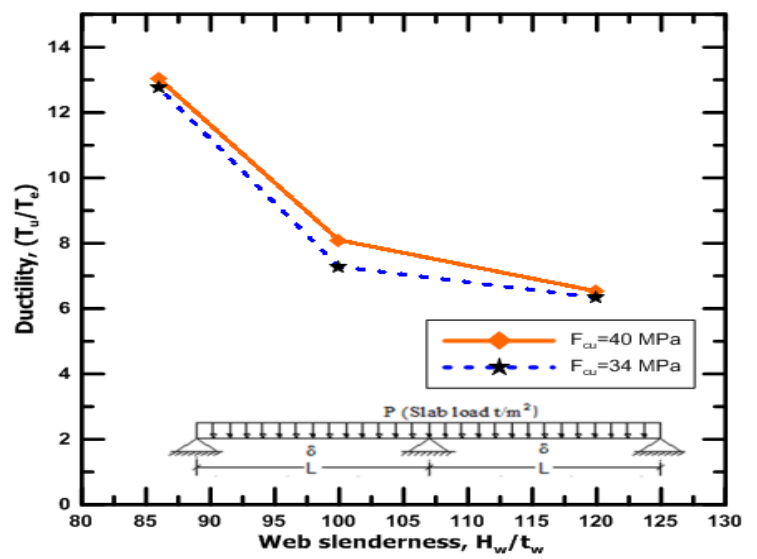

Fig 21: Effect of changes in concrete strength on ductility

As an example, increasing the concrete strength from $34 \mathrm{MPa}$ to $40 \mathrm{MPa}$, for $h_{w} / t_{w}=100$ (web status $\mathrm{D} *$ ), the percentage of increase in the ultimate load is $3 \%$. Regarding to the ductility, Figure 21 show the effect of concrete strength, where for beams with web status $\mathrm{D}^{*}$, the increase in ductility is small and some beams show no increase.

\subsection{Effect of Concrete Slab Thickness}

In this study, the effect of the variation of the concrete slab thickness is studied. Samples of the load deflection curves for beams with span to depth ratio=15 are shown in figure 22 . As shown in the load deflection curves, the variation of concrete slab thickness affected clearly the ultimate load, the ductility and the initial stiffness as will be explained.

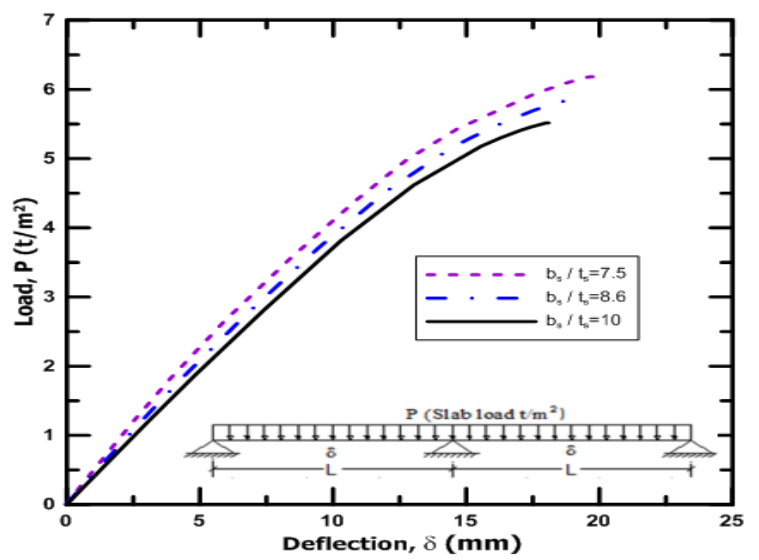

Fig 22: Load deflection curve of S60, S81 \& S87
The effect of slab thickness on the ultimate load is shown in figure 23 , where there is an obvious increase in the ultimate load, as an increase in the slab thickness would raise the neutral axis of the composite beams, hence increasing the lever arm of the section. For example, starting from $b_{s} / t_{s}=10$, for $h_{w} / t_{w}=86$ (web status $\mathrm{D}^{*}$ ), the percentage of increase in the ultimate load is $5.6 \%$ and $11.8 \%$ for $b_{s} / t_{s}=8.6$ and $b_{s} / t_{s}$ $=7.5$ respectively. Also a more ductile behavior can be obtained by $14 \%$ and $29 \%$, respectively (figure 24). Regarding to the initial stiffness, an increase in its values can be achieved by $10.3 \%$ and $23.1 \%$, respectively (figure 25 ).

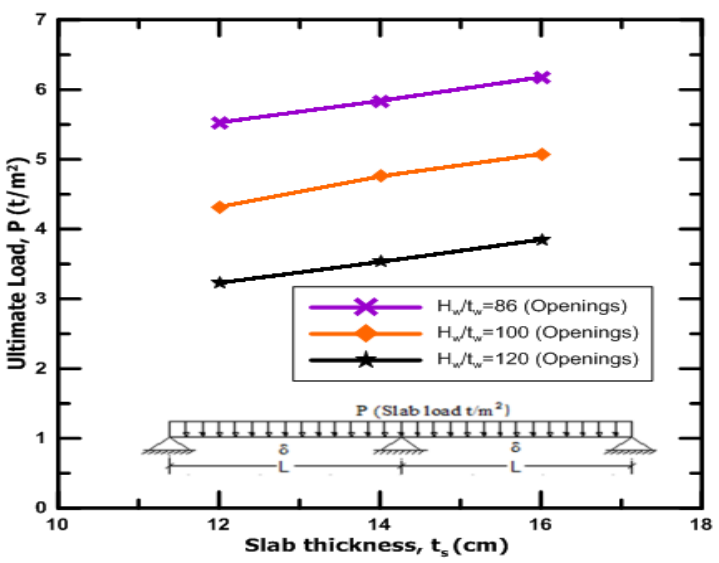

Fig 23: Effect of changes in concrete slab thickness on ultimate load

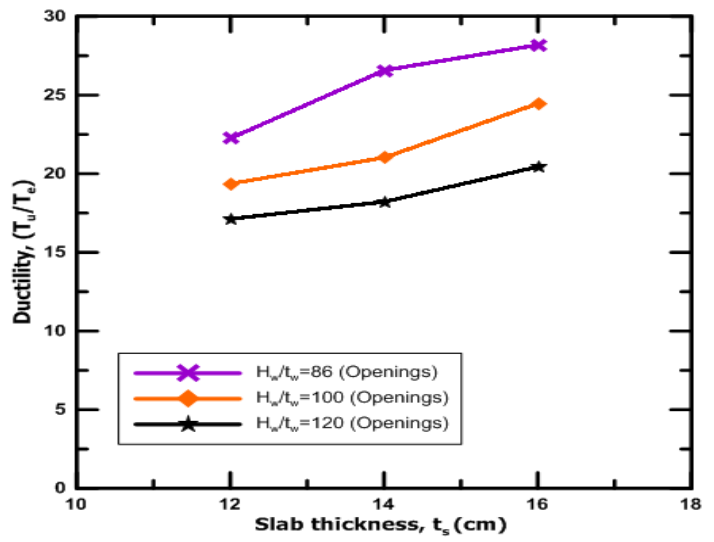

Fig 24: Effect of changes in concrete slab thickness on ductility

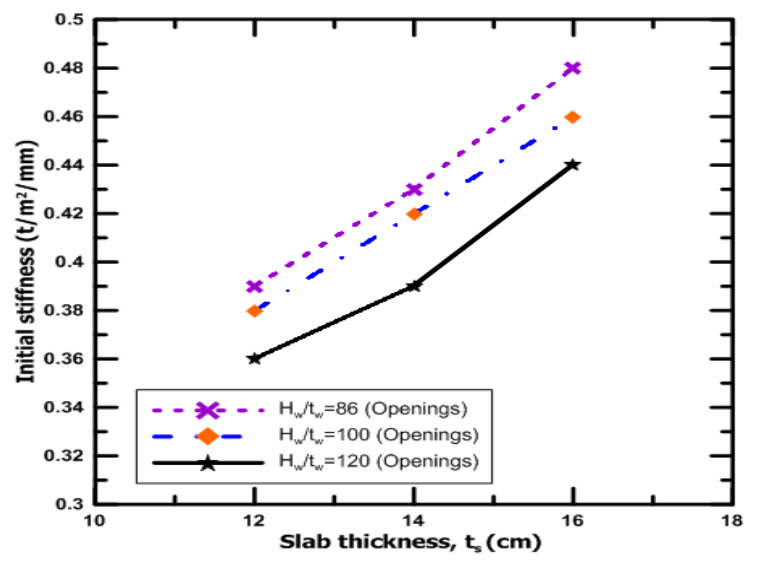

Fig 25: Effect of changes in slab thickness on initial stiffness 


\section{CONCLUSIONS AND RECOMMENDATIONS \\ 5.1 Conclusions}

1- The ultimate load of the composite castellated beam can be increased by $12 \%, 17 \%$ and $25 \%$ by using vertical stiffeners, stiffeners around the openings and starting the web openings after the negative moment region respectively.

2- An increase in the initial stiffness of the composite castellated beam by $2 \%, 10.5 \%$ and $18 \%$ can be achieved using using vertical stiffeners, stiffeners around the openings and starting the web openings after the negative moment region respectively.

3- Compared to the normal castellated beam, the ductility ratio decreases by $50 \%, 61.2 \%$ and $68.6 \%$ for vertical stiffeners, stiffeners around openings and starting the web openings after the negative moment region, respectively.

4- Increasing the steel strength to $f_{y}=275 \& f_{u}=430 \mathrm{MPa}$ and to $f_{y}=355 \& f_{u}=510 \mathrm{MPa}$ results in an increase in the ultimate load by $6.5 \%$ \& $18.5 \%$ respectively, and a decrease in the ductility by $18.5 \%$ \& $31 \%$ respectively.

5- The variation of concrete strength has almost no influence on the initial stiffness, while we can achieve a $4 \%$ increase in the strength and a $23 \%$ increase in the ductility by increasing the concrete strength from 34 to $40 \mathrm{MPa}$.

6- Decreasing the slab slenderness causes an increase in the ultimate load by $7 \%$ \& $14 \%$ for $b_{s} / t_{s}=8.6 \& b_{s} / t_{s}=7.5$, as an increase in the slab thickness would raise the neutral axis of the composite beams, hence increasing the lever arm of the section, also the ductility increases by $18.5 \%$ $\& 34 \%$ and initial stiffness increases by $6.5 \% \& 15 \%$ by increasing the slab thickness.

\subsection{Recommendations}

1- For modeling of partial shear connection, using the nonlinear elastic connector elements and Contact interactions gives the best solution.

2- After comparing the results of the changes that were done to the web, it can be recommended to start the web openings after the negative moment region to obtain the highest ultimate load and initial stiffness, and for the ductility, using vertical stiffeners is the best solution.

3- It is recommended to increase the concrete slab thickness other than increasing the concrete strength to enhance the behavior of the beams.

4- It is proposed to study the behavior of continuous composite castellated beams beams under dynamic loads, which can be our future scope.

\section{REFERENCES}

[1] Nethercot, D. A, Kerdal, D., (1982). Lateral torsional buckling of castellated beams. The Structural Engineer, 60B (3), 53-61.

[2] Larnach, J.W., and Park, R. (1964). The behavior under load of six castellated composite T-beams. Civ. Engng. and Pub. Works, 59:692, 339-343.

[3] Giriyappa, J. and Baldwin, J.W. (1966). Behavior of composite castellated hybrid beams. Univ. of Missouri Engng. Experimental Res. Station, Columbia.. Mo.,USA.
[4] Hartono. W., and Chiew. S.P. (1996). Composite behavior of half castellated beam with concrete top slab. Advances in Steel Structures. Proceedings of a conference in Hong Kong. Pergamon. Editors: S.L. Chan and J.G. Teng.pp 437-442.

[5] Megharief, J. D., (1997). Behavior of composite castellated beams. MSc thesis, McGill University, Montreal.

[6] Gizejowski, M. A., Salah, W., (2011). Numerical modeling of composite castellated beams. Proc. Local Seminar of the polish Chapter of IASS, Warsaw, 554565.

[7] Salah, W., Gizejowski, M. A., (2008a). Numerical finite element modeling of the stability behavior of slender section steel-concrete composite beams with web openings. Proc. Local Seminar of the polish Chapter of IASS, Warsaw, 76-86

[8] Salah, W., Gizejowski, M. A., (2008b). Experimental investigation of the stability behavior of slender section steel-concrete composite beams with web openings. Proc.Local Seminar of the polish Chapter of IASSWarsaw, 68-75.

[9] Gizejowski, M. A., Salah, W. (2007). Failure modes of composite beams in the hogging moment region of continuous or semi-continuous systems. Proc. Local Seminar of the Polish Chapter of IASS, Warsaw, 114136.

[10] Hibbitt, Karlsson and Sorensen, (2008). ABAQUS standard user's manual. Inc. vols. 1, 2 and 3. Version 6.8-1. USA.

[11] Gattesco, N., (1999). Analytical modelling of nonlinear behavior of composite beams with deformable connection. Journal of Constructional Steel Research, 52 195-218.

[12] Carreira, D.J., and Chu, K.H., (1985). Stress-Strain relationship for plain concrete in compression. ACI Struct.J., 82(11), 797-804.

[13] Baskar, K.; Shanmugam, N. E.; Thevendran, V. (2002). Finite element analysis of steel-concrete composite plate girder, Journal of Structural Engineering 128(9): 11581168.

[14] Liang, Q., Uy, B., Bradford, M. and Ronagh, H., (2005). Strength analysis of steel-concrete composite beams in combined bending and shear, Journal of Structural Engineering. ASCE, 131(10), 1593-1600.

[15] Ansourian P., (1981). Experiments on continuous composite beams. Proc. Inst. Civil Eng., Part 2, 25-51.

[16] Dabaon, M. A., (2002). Effective width of composite beam at region of negative moment. Scientific Bulletin, Ain Shams University, Faculty of Engineering, 37(1), 85-109.

[17] Donahey, R. C. and Darwin, D., (1986). Performance and design of composite beams with web opening. SM Report No. 18, University of Kansas Center for Research, Lawrence, Kansas, USA (April).

[18] Eurocode 4 (1992), ENV 1994-1-1:1992 - Design of composite steel and concrete structures Part - 1- 1: General rules and rules for buildings. Brussels

[19] Eurocode 3, (2007). Design of steel structures part 1-12: additional rules for the extension of EN 1993 up to steel grades S 700. London (UK): British Standards, Institution, BS EN 1993-1-12.

[20] Mashaly, E. M., Zien Eldin, H., El-Heweity, M., Ismail, R. and Ismail, H., (2010). Behavior of stub girder floor system with partial shear connection. Alexandria Engineering Journal 49,357-370. 